\title{
Abstinence from Cocaine Self-Administration Heightens Neural Encoding of Goal-Directed Behaviors in the Accumbens
}

\author{
Jonathan A Hollander' and Regina M Carelli*,' \\ 'Department of Psychology, The University of North Carolina at Chapel Hill, Chapel Hill, NC, USA
}

\begin{abstract}
Cocaine addiction in humans is characterized by cycles of abstinence from drug-taking and relapse. Here, electrophysiological recording procedures were used to determine whether nucleus accumbens (Acb) neuronal firing properties are altered following interruption and resumption of cocaine self-administration. Rats $(n=12)$ were trained to self-administer cocaine ( $2 \mathrm{~h}$ daily sessions) then divided into two groups. Acb activity was recorded for Group I (controls) during two additional self-administration sessions completed over the next 2 days (test sessions I and 2). Acb activity was recorded for Group 2 ( I-month) during one self-administration session completed the next day (test I), and during a second self-administration session I month later (test 2). As in prior reports, a subset of Acb neurons exhibited patterned discharges (short duration and/or long-term cyclic alterations, termed 'phasically active') relative to cocaine-reinforced responding during test session I. Remarkably, the percentage of phasically active cells dramatically increased (nearly two-fold) following I-month abstinence, in the core but not the shell of the Acb. Likewise, the strength of the neural correlates (determined via signal-tobaseline ratios) also increased as a function of abstinence. Extinction experiments in another set of rats $(n=12)$ revealed an increased motivational state for the drug following abstinence. The results show that abstinence from cocaine self-administration causes a dramatic increase in the number and strength of Acb neurons that encode cocaine-related information, thus representing the first neurophysiological correlate of heightened activation of the 'brain reward system' following abstinence and resumption (relapse) of cocaine consumption.
\end{abstract}

Neuropsychopharmacology (2005) 30, |464-1474, advance online publication, 27 April 2005; doi: I0.1038/sj.npp. I 300748

Keywords: addiction; electrophysiology; drug abuse; reward; relapse; motivation

While the typical pattern of cocaine addiction in humans is characterized by intermittent periods of abstinence from drug-taking followed by increased craving and relapse (Gawin, 1991; O’Brien, 1997), little is known about the neurobiological consequences of interrupted drug access for the cocaine user. The nucleus accumbens (Acb) and associated regions are part of the 'brain reward system' and considered key neural substrates underlying addiction (Koob and Le Moal, 1997, 2001; Ahmed and Koob, 2005; Everitt and Wolf, 2002; Ito et al, 2004; Wise, 1984). Recent studies have examined the effects of cocaine abstinence (withdrawal) on this system. For example, withdrawalrelated neuroadaptations have been reported in the Acb including glutamate-related cellular changes (Baker et al, 2003; Ghasemzadeh et al, 2003; Kalivas et al, 2003),

*Correspondence: Dr RM Carelli, Department of Psychology, The University of North Carolina at Chapel Hill, CB\# 3270, Davie Hall, Chapel Hill, NC 27599-3270, USA, Tel: + I 919962 8775, Fax: + I 919962 2537, E-mail: rcarelli@unc.edu

Received 28 September 2004; accepted 18 March 2005

Online publication: 23 March 2005 at http://www.acnp.org/citations/ Npp032305040450/default.pdf alterations in gene expression (Toda et al, 2002), and alterations in GABA concentration (Xi et al, 2003). Likewise, structural changes in Acb medium spiny neurons have been observed following 1 month removal of cocaine (Robinson et al, 2001). Importantly, 1-month abstinence from cocaine self-administration resulted in numerous neuroadaptations including changes in cAMP dependent protein kinase, adenylate cyclase, tyrosine hydroxylase and alterations in various glutamate receptor subunits in the ventral tegmental area and/or Acb (Lu et al, 2003).

Electrophysiological investigations in cocaine self-administering rodents have provided important insight into cellular mechanisms underlying drug-directed behaviors independent of abstinence. Those studies revealed that, in well-trained animals, a subset of Acb neurons exhibit changes (increases and/or decreases) in firing rate timelocked to lever press responding for intravenous cocaine that occur within two distinct time domains. First, a subset of Acb neurons exhibit rapid changes (increases or decreases) in activity within seconds of lever press responding for cocaine (Carelli et al, 1993; Carelli, 2002; Chang et al, 1994; Peoples and West, 1996; Uzwiak et al, 1997) that appear to reflect associative aspects of the 
self-administration task. For example, Acb neurons that discharge within seconds before the reinforced response for cocaine appear to encode 'anticipation' of impending drug reward (Carelli et al, 1993; Carelli, 2002; Carelli and Ijames, 2000). In contrast, Acb neurons that exhibit changes in firing rate within seconds following response completion are related to the association of lever pressing and reward, and are also activated by stimuli paired with drug infusion (Carelli and Ijames, 2001; Carelli, 2000). Second, some Acb neurons exhibit long-term cyclic alterations in cell firing that occur on the order of minutes within the entire interinfusion interval (Peoples and West, 1996; Peoples et al, 1998a, b; Carelli, 2002). It has been proposed that these long-term discharges may be a neurophysiological mechanism that translates declining drug levels to increased motivation for the drug and, consequently, increased drug-seeking behavior (Peoples and West, 1996).

Given these findings, we examined whether Acb patterned discharges are altered during resumption of cocaine selfadministration following 0 (control) or 1-month experimenter-imposed abstinence. This study differs from previous work because Acb cell firing is examined during resumption of cocaine self-administration following a period of drug abstinence. Furthermore, extinction studies were completed in another set of rats to determine whether an enhanced motivation for the drug exists following abstinence that is masked when animals are given free access to the drug, as in our electrophysiology study. Collectively, our findings examine whether an enhanced activation of the Acb related to heightened motivation for the drug exists following abstinence and resumption (relapse) of cocaine consumption.

\section{MATERIALS AND METHODS}

\section{Subjects}

Male, Sprague-Dawley rats (Harlan), approximately 90-120 days old (275-350 g) were used as subjects $(n=24)$. Animals were housed individually and maintained at no less than $85 \%$ of their preoperative body weight by regulation of water intake, described previously (Carelli et al, 2000). Under ketamine hydrochloride $(100 \mathrm{mg} / \mathrm{kg})$ and xylazine hydrochloride $(20 \mathrm{mg} / \mathrm{kg})$ anesthesia, all animals were surgically prepared for self-administration via implantation of a catheter into the jugular vein using established procedures (Carelli and Deadwyler, 1994; Caine et al, 1993).

\section{Surgery and Cocaine Self-Administration}

A subset of animals $(n=12)$ were also prepared for extracellular recording in the Acb via implantation of microwire electrode arrays within the same surgery as catheter implantation using established procedures (Carelli and Deadwyler, 1994; Caine et al, 1993). Each array was custom-designed, purchased from a commercial source (NB Labs, Denison, TX) and described in detail elsewhere (Carelli et al, 2000). Each array consisted of eight microwires $(50 \mu \mathrm{m}$ diameter $)$ and was permanently implanted bilaterally into the Acb (AP: $+1.7 \mathrm{~mm}, \mathrm{ML}: 1.5 \mathrm{~mm}$, DV: $6.0-7.5 \mathrm{~mm}$, relative to bregma, level skull). All surgical procedures were approved by the UNC Institutional Animal Care and Use Committee (IACUC) and in concordance with the NIH Guide for the Care and Use of Animals.

At 1 week following surgery, animals were trained to selfadminister cocaine during daily $2 \mathrm{~h}$ sessions conducted in a $43 \times 43 \times 53 \mathrm{~cm}^{3}$ Plexiglas chamber (Med. Associates, Inc., St Albans, VT) housed within a commercial soundattenuated cubicle (Fibrocrete, Inc., Crandall, GA). The beginning of the self-administration session was signaled by the onset of a cue light positioned $6.5 \mathrm{~cm}$ above a lever and lever extension. Lever depression on an FR1 schedule resulted in intravenous cocaine delivery $(0.33 \mathrm{mg} /$ infusion, dissolved in sterile heparinized saline vehicle) over a $6 \mathrm{~s}$ period via a computer controlled syringe pump (Model PHM-100, Med Associates, Inc., St. Albans, VT). Initiation of drug delivery was signaled by termination of the cuelight and simultaneous onset of a tone $(67 \mathrm{db}, 1 \mathrm{kHz})$ houselight $(25 \mathrm{~W})$ stimulus complex $(20 \mathrm{~s})$. Training was complete when stable responding was established (ie $<10 \%$ variability in press number during a consecutive 10-day period; 2-3 weeks).

Next, animals were randomly divided into two groups (6 rats/group) and Acb cell firing was recorded during two test sessions as follows. Group 1 (controls) continued to lever press for two additional consecutive days following cocaine self-administration training (ie test sessions 1 and 2). For these animals, no experimenter-imposed abstinence was given beyond the normal $24 \mathrm{~h}$ between each session thus controlling for duration of abstinence. For Group 2, Acb cell firing was recorded during one additional selfadministration session following training (test session 1), then animals underwent a 1-month abstinence period during which drug access was interrupted (animals remained in their home cages). Following 1-month abstinence, animals were placed back in the experimental chamber and Acb neurons were recorded during completion of a single self-administration session (test session 2).

\section{Electrophysiological Recordings}

Electrophysiological procedures have been described in detail previously (Carelli and Deadwyler, 1994; Carelli et al, 2000). Briefly, before the start of each session, the subject was connected to a flexible recording cable attached to a commutator (Med Associates Inc., St Albans, VT), which allowed virtually unrestrained movement within the chamber. The headstage of each recording cable contained 16 miniature unity-gain field effect transistors. Acb activity was recorded differentially between each active and the inactive (reference) electrode from the permanently implanted microwires. The inactive electrode was examined before the start of the session to verify the absence of neuronal spike activity and served as the differential electrode for other electrodes with cell activity. Online isolation and discrimination of neuronal activity was accomplished using a neurophysiological system commercially available (multichannel acquisition processor, MAP System, Plexon, Inc., Dallas, TX). Multiple window-discrimination modules and high-speed analog-to-digital (A/D) signal processing in conjunction with computer software enabled isolation of neuronal signals based on waveform analysis. The neurophysiological system 
incorporated an array of digital signal processors (DSPs) for continuous spike recognition. The DSPs provided a continuous parallel digital output of neuronal spike events to a Pentium computer. Another computer controlled behavioral events of the experiment (Med Associates Inc., St Albans, VT) and sent digital outputs corresponding to each event to the MAP box to be time stamped along with the neural data. Here, Acb activity was examined as population data, and we did not attempt to record the same neurons across test sessions.

The neurophysiological system has the capacity of recording up to four neurons per microwire using realtime discrimination of neuronal extracellular action potentials. In the present study, the majority of neurons were recorded from different wires (66-72\%, depending upon test session) and this remained consistent following abstinence. Criteria for identifying individual neurons on the same or different wires have been described in detail elsewhere (Carelli et al, 1999, 2000; Chang et al, 1994; Nicolelis et al, 1997, 1999). Briefly, discrimination of individual waveforms began by setting a threshold level (well above background noise) for each wire. Waveform amplitudes ranged from 100 to $250 \mu \mathrm{V}$ and were remarkably similar across test sessions and groups. The consistency in waveform amplitude was confirmed by a two-way ANOVA that revealed no significant main effect of group $\left(\mathrm{F}_{1,200}=0.54, p>0.05\right)$, test session $\left(\mathrm{F}_{1,200}=1.41, p>0.05\right)$ or interaction of group $\times$ test session $\left(F_{1,200}=0.002\right.$, $p>0.05)$ on mean waveform amplitude. Individual waveforms corresponding to a single cell were discriminated using template analysis procedures and time-voltage boxes provided by the neurophysiological software system (MAP system, Plexon, Inc., Dallas, TX). The template analysis procedure involves taking a 'sample' of the waveform and building a template of that extracellular waveform using real-time principle component analysis. Subsequent neurons that 'match' this waveform are included as the same cell. When using time-voltage boxes, a sample of the waveform is taken, then the experimenter superimposes two boxes onto it (typically one on the ascending limb and the other on the descending limb of the extracellular waveform). Subsequent sampled neurons are accepted as valid when they pass through both boxes. As such, waveforms of different neurons recorded from the same (or different) wires were discriminated based on a variety of parameters including peak amplitude, waveform width, latency to peak, polarity and duration of the extracellular action potential. The parameters for isolation and discrimination of singleunit activity were determined and saved before test 1 using the neurophysiological software and also used for test session 2. Mean overall firing rates $(1.78 \pm 0.03 \mathrm{~Hz})$ remained remarkably similar across groups and test sessions. Specifically, a two-way ANOVA revealed no significant main effect of group $\left(\mathrm{F}_{1,200}=0.45, p>0.05\right)$, test session $\left(\mathrm{F}_{1,200}=0.03, p>0.05\right)$ or interaction of group $\times$ test session $\left(\mathrm{F}_{1,200}=0.06, p>0.05\right)$ on mean firing rates.

\section{Data Analysis}

Neural activity was characterized via raster displays and perievent histograms (PEHs) showing the activity of each cell across two distinct time domains that bracketed cocaine-reinforced responses. First, Acb cell firing was classified into one of four well-defined types of neuronal firing patterns that occurred within seconds of the reinforced response, using established protocols described in detail previously (Carelli et al, 2000). Specifically, firing patterns were characterized by an anticipatory increase in activity preceding the reinforced response (type preresponse, $\mathrm{PR}$ ), and either increases (type reinforcement-excitation, $\mathrm{RFe}$ ) or decreases (type reinforcementinhibition, RFi) in firing immediately following response completion. A fourth type of neuronal firing pattern (type $\mathrm{PR}+\mathrm{RF}$ ) exhibited a dual peak increase; the first peak occurred before and the second immediately following response completion with a marked inhibition between the two peaks (Carelli and Wightman, 2004). Extensive investigations have revealed that these firing patterns reflect associative aspects of the self-administration task with preresponse discharges encoding 'anticipation' of impending drug reward and postresponse firing reflecting the response-reinforcer contingency of the task and drugassociated cues (Carelli and Wightman, 2004). Neurons were classified as type PR, RFe, RFi, PR + RF based on $40 \%$ changes (increases or decreases) in peak firing rate within a $20-s$ period that bracketed the reinforced response, compared to baseline activity (for detailed methodology see Carelli et al, 2000). The baseline period included -10 to $-7.5 \mathrm{~s}$ prior to the lever press and did not vary across neurons or sessions (Carelli et al, 2000). Statistical confirmation of cell type classification was accomplished using paired $t$-tests comparing mean peak (Type PR, RFe, $\mathrm{PR}+\mathrm{RF}$ ) or trough (Type $\mathrm{RFi}$ ) firing rates for all neurons to their respective baselines rates $(p<0.05)$. Second, Acb neurons were classified into one of two types of neuronal firing patterns characterized by long-term cyclic alterations that spanned the entire inter-infusion interval of the selfadministration sessions. Specifically, long-duration cyclic discharges were characterized by an anticipatory increase in activity occurring within minutes preceding the reinforced response (type Long, pre-response, LongPR), or increases in firing rate that began immediately following the response but continued over minutes (type Long, reinforcementexcitation, LongRFe). In this case, however, the time interval included in each PEH: (1) approximated each animal's interinfusion interval (INT), (2) did not include overlap in neural activity displayed for consecutive lever presses and (3) excluded the first 3-6 erratically-spaced lever presses constituting the 'load-up' phase of the selfadministration session (Carelli et al, 1999). For these cells, PEH's were constructed with a bin width of $0.5 \mathrm{~s}$ while the INT varied among rats. Neurons were grouped as type LongPR or LongRFe based on $40 \%$ peak increases in firing rate relative to the reinforced response, compared to baseline activity. To determine peak (signal) and baseline values, each $\mathrm{PEH}$ was divided into eight equal time components (from left to right). Baseline always included the first component of each PEH whereas peak (signal) included the fourth (type LongPR) or fifth (type LongRFe) components. Since interinfusion intervals varied across animals, the exact time interval for peak (signal) and baseline ranged from 50 to $97 \mathrm{~s}$ (100-195 bins). Importantly, baseline occurred during a period in each $\mathrm{PEH}$ in which phasic activity had not yet begun. Statistical confirmation of 
cell type classification was accomplished using paired $t$-tests comparing mean peak firing rates for all neurons to their respective baselines rates $(p<0.05)$. 'Nonphasic' neurons exhibited similar firing rates across all analysis time intervals.

Neurons were classified as either nonphasic, one of the four types of short duration patterned discharges and/or one of the two types of long-term cyclic alterations during the test sessions which included: (1) the two consecutive days following training (controls) or (2) during the last selfadministration session following training and first session following 1-month of abstinence (abstinence group). Once cell type classification was complete, the percentages of each type of patterned discharge were determined for each test session across animals and averaged to obtain a mean phasic percentage value shown in the figures.

To quantify the strength of each neural correlate as a function of abstinence, signal-to-baseline $(S: B)$ ratios were calculated for each neuron recorded for the 1-month abstinence group. S:B ratios were determined by dividing the mean firing rate during the peak of the response for each phasic neuron (ie the signal) by its respective baseline rate. $\mathrm{S}: \mathrm{B}$ ratios were established during the last selfadministration session following training and first session following 1-month of abstinence.

\section{Histology}

Following completion of the last experiment, rats were anesthetized with ketamine hydrochloride $(150 \mathrm{mg} / \mathrm{kg})$ and xylazine hydrochloride $(20 \mathrm{mg} / \mathrm{kg})$, and a $10 \mu \mathrm{A}$ current was passed for $6 \mathrm{~s}$ through all recording wires. Rats were perfused, brains removed, blocked and sectioned $(40 \mu \mathrm{m})$ throughout the rostral-caudal extent of the Acb. Sections were stained for thionin and counterstained with potassium ferracyanide to reveal a blue dot reaction product corresponding to the location of the marked electrode tip (Green, 1958; Carelli et al, 2000). To reconstruct electrode positions, serial sections were examined under a light microscope and the locations of all marked electrode tips were plotted for all subjects on coronal sections taken from the stereotaxic atlas of Paxinos and Watson (1998). Only neurons recorded from wires positioned in the Acb were used in the present study. $\chi^{2}$ tests were completed to determine whether there were significant differences in the number of phasic neurons recorded for each condition across subregions (core $v s$ shell) of the Acb.

\section{Extinction}

After the establishment of stable self-administration, behavioral responding was examined (no electrophysiology) in another set of rats $(n=12)$ during a single extinction session completed the next day $(n=6)$ or following 1-month abstinence $(n=6)$. For the abstinence group, animals remained in their home cages without access to drug for 1 month. For all animals, two levers were inserted into the chamber during training, an 'active' and an 'inactive' lever. Lever presses on the active lever resulted in intravenous cocaine infusion $(0.33 \mathrm{mg} / \mathrm{inf})$, termination of the cuelight over the lever $(20 \mathrm{~s})$ and onset of a tonehouselight stimulus complex $(20 \mathrm{~s})$. Responses on the inactive lever had no programmed consequences (ie drug was not infused, and no changes occurred in audio or visual parameters). The extinction session consisted of two phases ( $2 \mathrm{~h} /$ phase). During phase one, lever depression had no programmed consequences. After $2 \mathrm{~h}$, Phase 2 was initiated via a priming infusion of cocaine $(0.33 \mathrm{mg} / \mathrm{inf} ; 6 \mathrm{~s})$ paired with termination of the cuelight $(20 \mathrm{~s})$ and simultaneous onset of the tone- $(67 \mathrm{db}, 1 \mathrm{kHz})$ houselight $(25 \mathrm{~W})$ stimulus complex $(20 \mathrm{~s})$. All subsequent responses on the lever previously associated with cocaine (ie the 'active' lever) resulted in presentation of the audiovisual stimuli only (ie cuelight off, tone-houselight on, $20 \mathrm{~s}$ ). Again, responding on the 'inactive' lever had no programmed consequences.

\section{RESULTS}

\section{Behavior}

Cumulative records of lever press responses during test selfadministration sessions for a representative control animal and an animal that underwent 1-month experimenterimposed abstinence from cocaine self-administration are illustrated in Figure 1a. Across all rats, results show that animals that underwent 1-month abstinence exhibited

a
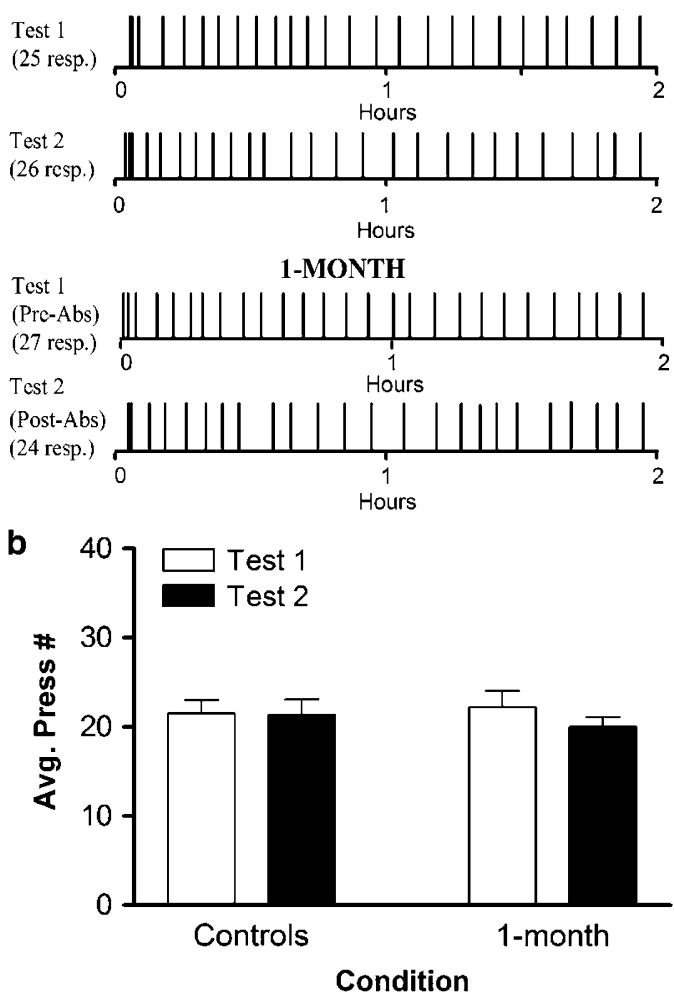

Figure I Similar behavioral (lever press) response patterns during cocaine self-administration sessions before versus following abstinence. (a) Representative behavioral records for a single animal within each group (control vs I-month) show lever press responding for intravenous cocaine ( $0.33 \mathrm{mg} / \mathrm{inf} ; 2 \mathrm{~h}$ ) across the test sessions. For the control animal, the test 2 record denotes responding during the self-administration session the day after the test I session. For the I-month animal, the test 2 record denotes responding during the self-administration session I month after the test I session. Each cocaine-reinforced response is indicated by vertical lines in the records. (b) Average number of lever presses for all animals in each condition across test sessions. 
almost identical behavioral profiles as control animals. Specifically, as illustrated in Figure 1b, a two-way ANOVA revealed no significant main effect of group $\left(\mathrm{F}_{1,20}=0.021\right.$, $p>0.05)$, test session $\left(\mathrm{F}_{1,20}=2.842, p>0.05\right)$ or interaction of group $\times$ test session $\left(\mathrm{F}_{1,20}=2.527, p>0.05\right)$ on lever press responses during test self-administration sessions.

However, it was possible that any changes in the motivational state of the animals following 1-month abstinence were masked since drug was freely available during the postabstinence $2 \mathrm{~h}$ self-administration test session. Therefore, in order to determine whether animals were more motivated to obtain drug as a consequence of abstinence another set of rats $(n=12)$ were trained to selfadminister cocaine as before, and then completed an extinction session following $0-$ (control) or 1-month abstinence. Figure 2a shows the behavioral profile of one representative animal for each group, while Figure $2 \mathrm{~b}$ shows the average number of presses for all animals across the two

a
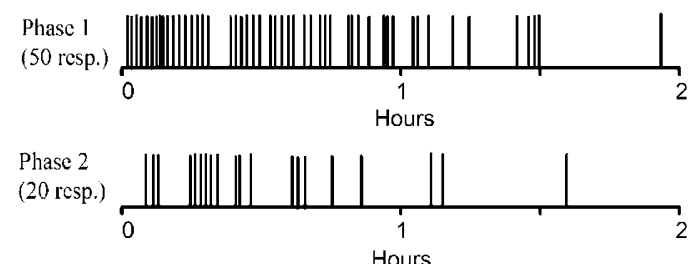

1-MONTH
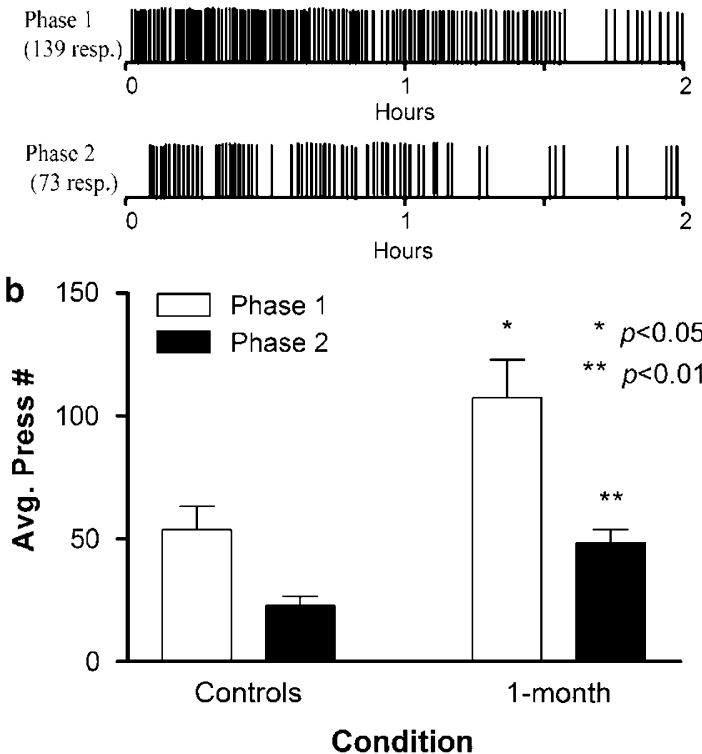

Figure 2 Increased resistance to extinction following abstinence from cocaine self-administration. (a) Representative behavioral records for a single animal within each group (control vs I-month) show lever press responding on the lever previously associated with cocaine (active lever) across the two phases of extinction. During phase I each response had no programmed consequences. During phase 2 each lever press resulted in presentation of audiovisual cues previously paired with cocaine. (b) Average number of responses on the active lever for each group (control vs I-month) during each phase of extinction. For controls, the extinction session was conducted the day following cocaine self-administration training; for the I-month group extinction occurred I-month following self-administration training. Asterisks indicate a significant increase from control levels for each phase. phases of extinction. A two-way ANOVA of 'active' lever presses during extinction revealed a significant difference in the number of presses as a function of session phase $\left(\mathrm{F}_{1,20}=16.681, p<0.01\right)$ and group $\left(\mathrm{F}_{1,20}=13.002, p<0.01\right)$ with no interaction between session phase $\times$ group $\left(\mathrm{F}_{1,20}=1.648, p>0.05\right)$. Post hoc Fisher's LSD revealed that the 1-month abstinent animals had a significant increase in lever press responding during phase 1 in which no cues or drug were given $\left(t_{10}=2.715, p<0.05\right)$ and phase 2 during which animals responded for drug-associated stimuli $\left(t_{10}=3.430, p<0.01\right)$ compared to controls. Importantly, responding on the inactive lever was negligible during both phases of extinction for both groups (ranging from 0 to 6 responses). Consistent with this findings, a two-way ANOVA revealed no significant differences in 'inactive' lever presses as a function of session phase $\left(\mathrm{F}_{1,20}=0.362\right.$, $p>0.05)$ or group $\left(\mathrm{F}_{1,20}=2.223, p>0.05\right)$.

\section{Heightened Activation of Accumbens Neurons following Cocaine Abstinence}

The extinction data confirm that following 1-month of abstinence, animals are more motivated to respond for cocaine. Since cocaine addiction in humans involves resumption of drug taking following abstinence, Acb cell firing was examined here during free access to cocaine selfadministration following abstinence (ie animals used in Figure 1). Importantly, since no changes in behavior were observed using this approach as verified above, any alterations in Acb cell firing could not be attributed to alterations in movement (ie increased lever pressing) following abstinence but instead likely reflect enhanced motivation for the drug.

A major finding reported here is that 1 month abstinence from cocaine self-administration significantly increased the number, percentage and strength of short-duration patterned discharges and long-term cyclic alterations exhibited by Acb neurons. These findings are discussed in detail below. Importantly, changes in cell firing following abstinence could not be attributed to discrepancies in cocaine history since no significant differences in amount of drug consumed were observed prior to testing between the two groups $\left(t_{10}=0.313, p>0.05\right)$.

\section{Short-Term Patterned Discharges}

In total, 103 neurons were recorded during the first test session (51 cells for controls; 52 neurons for the 1-month group). Of 103 cells, 20 neurons (19\%) exhibited one of the four types of well-documented short-duration patterned discharges illustrated in the PEHs in Figure 3a prior to abstinence (ie test session 1). Of the 20 phasic cells, seven neurons $(35 \%)$ exhibited increased firing within seconds preceding the reinforced response and were classified as type PR. Other neurons displayed significant increases (type RFe; six neurons, $30 \%$ ) or decreases (type RFi; five neurons; $25 \%$ ) in activity following the response, or a dual peak discharge (type PR $+\mathrm{RF}$, two cells; 10\%).

An important and clinically relevant issue addressed here is whether the incidence of these patterned discharges remain the same or increase following experimenterimposed abstinence. Remarkably, there was a dramatic 
increase (nearly two-fold) in the percentage of neurons exhibiting short-duration patterned discharges (types PR, $\mathrm{RFe}, \mathrm{RFi}$ and PR $+\mathrm{RF}$ ) following 1-month abstinence (18 of 50 cells, $36 \%$ ), but not for controls (nine of 51 cells, $18 \%$ ), summarized in Figure 3b. A two-way ANOVA revealed a significant main effect of test session $\left(\mathrm{F}_{1,20}=6.138, p<0.05\right)$ and group $\left(\mathrm{F}_{1,20}=11.787, p<0.01\right)$, with a significant interaction between test session $\times$ group $\left(\mathrm{F}_{1,20}=4.736\right.$, $p<0.05)$. Post hoc Fisher's LSD revealed a significant increase in the percentage of phasic cells pre vs post abstinence within the 1 -month group $\left(t_{10}=3.079, p<0.05\right)$ but not between the test sessions for the control group $\left(t_{10}=0.230, p>0.05\right)$.

Furthermore, there was a significant increase in the occurrence of all four types of neuronal firing patterns (types $\mathrm{PR}, \mathrm{RFe}, \mathrm{RFi}$ and $\mathrm{PR}+\mathrm{RF}$ ) for the 1-month abstinence group, confirming that more Acb cells are recruited to encode all aspects of the goal-directed behavior following abstinence (Figure 3c). Specifically, a two-way ANOVA revealed a significant main effect of test session $\left(\mathrm{F}_{1,40}=5.105, p<0.05\right)$, indicating that all four types of neuronal firing patterns increased following abstinence. No significant main effect of cell type $\left(\mathrm{F}_{3,40}=2.242, p>0.05\right)$ or interaction of cell type $\times$ test session was observed $\left(\mathrm{F}_{3,40}=0.401, p>0.05\right)$.

To determine whether the strength of the neural correlate was altered following abstinence, $\mathrm{S}: \mathrm{B}$ ratios for each phasically active cell were determined before versus following 1-month abstinence. A significant increase in $\mathrm{S}: \mathrm{B}$ ratio was observed for neurons exhibiting excitatory responses (type $\mathrm{PR}, \mathrm{RFe}$ and $\mathrm{PR}+\mathrm{RF}$ ) following 1 month abstinence from cocaine $\left(t_{21}=2.119, p<0.05\right)$. Importantly, this increase in $S: B$ was due to significant increases in 'signal' $(2.70 \pm 0.47 \mathrm{~Hz}$ prior to abstinence versus $4.14 \pm 0.44 \mathrm{~Hz}$ following abstinence, $\left.t_{21}=2.14, p<0.05\right)$ then baseline $(1.47 \pm 0.26 \mathrm{~Hz}$ before versus $1.66 \pm 0.27 \mathrm{~Hz}$ following abstinence, $\left.t_{21}=0.47, p>0.05\right)$. For neurons displaying a decline in cell firing within seconds of the reinforced response for cocaine (type RFi cells), a 60\% more phasic inhibition was observed following abstinence (ie representing a more enhanced inhibition). However, this finding was not significant $\left(t_{3}=1.953, p>0.05\right)$ perhaps related to the low number of type RFi cells. Nevertheless, these findings reveal that not only do the total number of short duration patterned discharges increase following abstinence, but that the strength of each neural correlate is enhanced.

\section{Long-Term Cyclic Alterations}

Of 103 neurons recorded prior to abstinence (51 cells for controls; 52 neurons for the 1-month group), 14 cells (14\%) exhibited one of the two types of long-term cyclic alterations illustrated in the PEHs in Figure 4a. Of the 14 phasically active cells, 10 neurons (71\%) exhibited increased firing within minutes preceding the reinforced response and were classified as type LongPR. Other neurons displayed a significant increase (type LongRFe; four neurons, 29\%) in activity following the response.

There was a dramatic increase in the percentage of neurons exhibiting long-term cyclic alterations (types LongPR, and LongRFe) following 1-month abstinence (13 of 50 cells, $26 \%$ ) but not for controls (nine of 51 cells, $18 \%$ ),
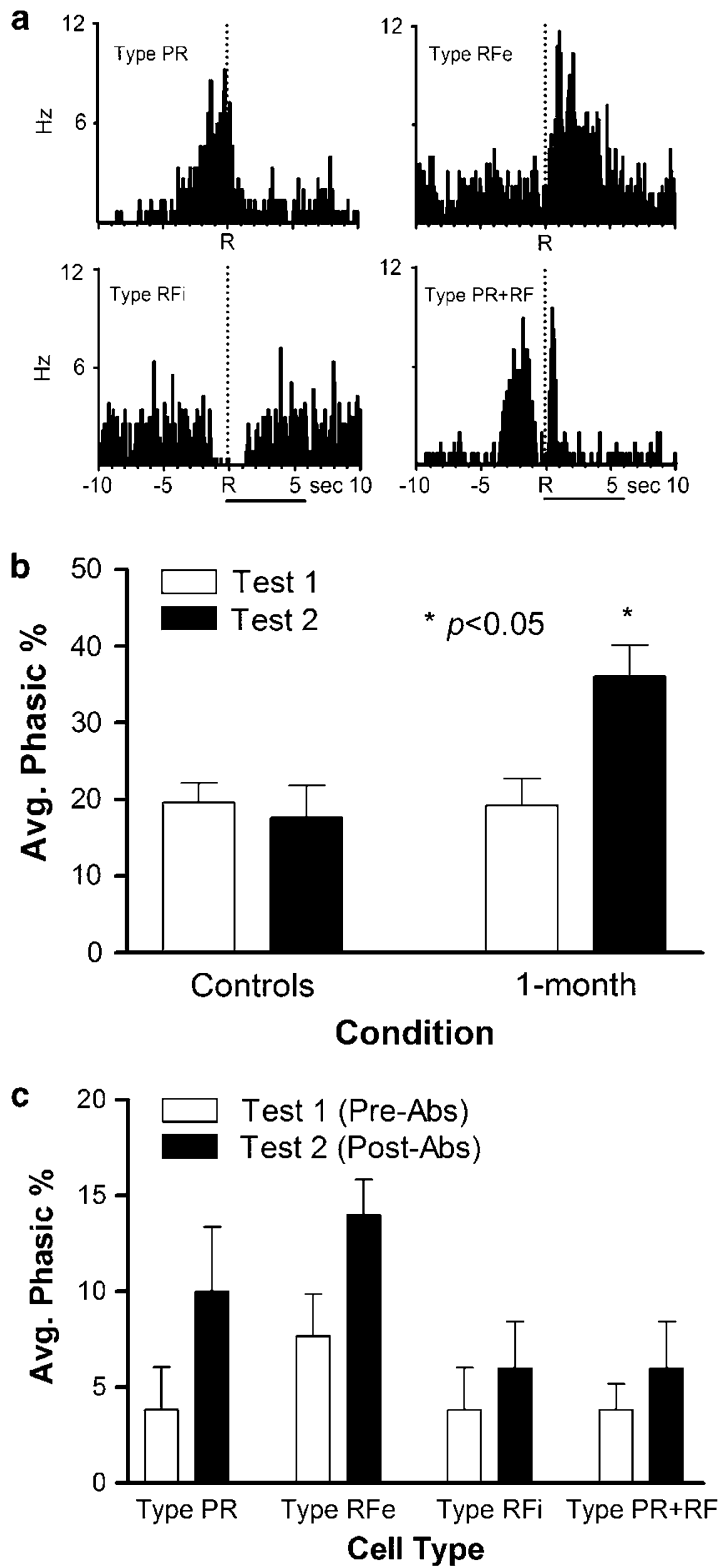

Figure 3 Increased incidence of Acb short-duration patterned discharges (types PR, RFe, RFi, PR + RF) following abstinence. (a) Examples of the four types of well-documented Acb neuronal firing patterns observed relative to the reinforced response for cocaine. Reinforced responses are indicated by $\mathrm{R}$ at dashed lines in $\mathrm{PEH}$. Duration of cocaine delivery $(0.33 \mathrm{mg} /$ infusion, $6 \mathrm{~s})$ is indicated by the horizontal line below the bottom PEHs. (b) The average percentage of Acb neurons (phasic \%) exhibiting short-duration patterned discharges as a function of group. For controls, Acb cell firing was examined during two consecutive days following cocaine self-administration training (ie test I and test 2). For I-month, Acb cell firing was recorded during one additional self-administration session immediately following training (test I) and I-month later (test 2). Asterisks indicate a significant increase during test 2 compared to test I for the I-month group. (c) Average percentage of neurons exhibiting one of the four types of neuronal firing patterns (ie phasic activity) prior to (test I) and following (test 2) I-month abstinence.

summarized in Figure 4b. A two-way ANOVA revealed a significant main effect for test session $\left(\mathrm{F}_{1,20}=4.623\right.$, $p<0.05)$, no significant main effect of group $\left(\mathrm{F}_{1,20}=1.524\right.$, $p>0.05)$, with a significant interaction between group $\times$ test 
a
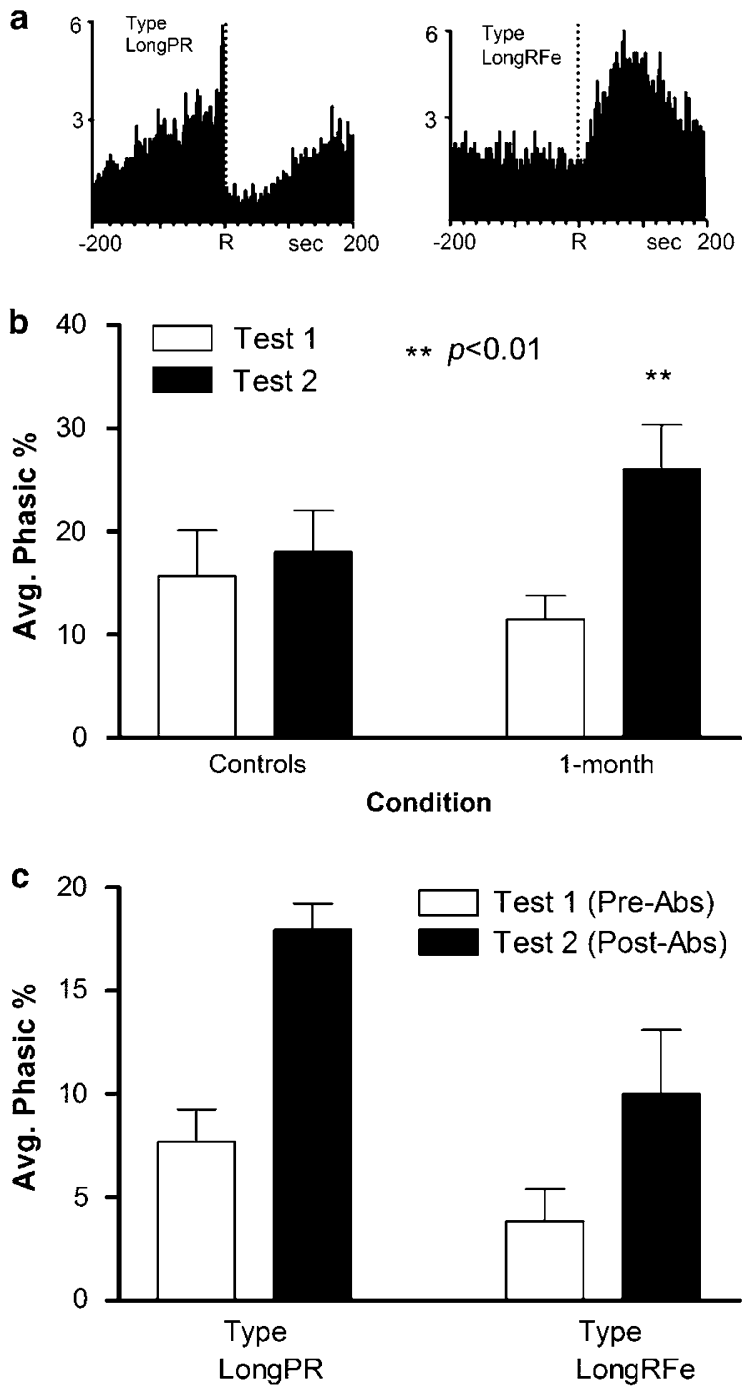

Cell Type

Figure 4 Increased incidence of Acb neurons exhibiting long-term cyclic alterations (types LongPR, LongRFe) following abstinence. (a) Examples of the two types of long-term cyclic discharges observed relative to the reinforced response for cocaine. Cocaine-reinforced responses are indicated by the ' $R$ ' at the dashed line in the PEHs. Baseline time epoch for these cells was -200 to $-150 \mathrm{~s}$. (b) The average percentage of Acb neurons exhibiting long-duration patterned discharges (phasic \%) as a function of group. For controls, Acb cell firing was examined during two consecutive days following cocaine self-administration training (ie test I and test 2). For I-month, Acb cell firing was recorded during one additional selfadministration session immediately following training (test I) and I-month later (test 2). Asterisks indicate a significant increase during test 2 compared to test I for the I-month group. (c) Average percentage of neurons exhibiting one of the two types of long-term cyclic alterations prior to (test I) and following (test 2) I-month abstinence.

session $\left(\mathrm{F}_{1,20}=4.589, p<0.05\right)$. Post hoc Fisher's LSD revealed a significant increase in the percentage of phasic cells across the test sessions within the 1 -month $\left(t_{10}=4.652\right.$, $p<0.01)$, but not the control group $\left(t_{10}=0.005, p>0.05\right)$. There was also a significant increase in the incidence of both types of long-term cyclic alterations (types LongPR and LongRFe) for the 1-month abstinence group (Figure 4c). Specifically, a two-way ANOVA revealed a significant main effect for test session $\left(\mathrm{F}_{1,20}=5.628\right.$, $p<0.05)$, indicating that the two types of neuronal firing patterns increased following abstinence. No significant main effect of cell type $\left(\mathrm{F}_{1,20}=3.161, p<0.05\right)$ or interaction of cell type $\times$ test session was observed $\left(\mathrm{F}_{1,20}=0.625\right.$, $p>0.05$ ).

To determine whether the strength of the neural correlates for this population of Acb cells was altered following abstinence, $\mathrm{S}: \mathrm{B}$ ratios for each neuron exhibiting long-term cyclic alterations were determined before versus following 1 -month abstinence. A significant increase $(42 \%$, $\left.\mathrm{t}_{17}=2.399, p<0.05\right)$ was observed in $\mathrm{S}: \mathrm{B}$ ratios for LongPR and LongRFe neurons following abstinence from cocaine. This increase in $S: B$ ratio was due to a significant increase in 'signal' $(1.42 \pm 0.20 \mathrm{~Hz}$ prior to abstinence compared to $2.65 \pm 0.29 \mathrm{~Hz}$ following abstinence, $t_{16}=3.33, p<0.01$ ) but not 'baseline' $(0.93 \pm 0.14 \mathrm{~Hz}$ before versus $1.32 \pm 0.17 \mathrm{~Hz}$ following abstinence, $\left.t_{16}=1.61, p>0.05\right)$ firing rates across abstinence.

A summary of the heightened activation of Acb neurons exhibiting short-term patterned discharges and/or longterm cyclic alterations is shown in pie charts in Figure 5. During the first test session for the control group, 17 cells (34\%) of Acb neurons displayed phasic activity (ie those neurons displayed short duration patterned discharges, long-term cyclic alterations or both). For this group (controls), the number (16 cells) and percentage (32\%) remained similar the next day (test session 2). In contrast, for the 1-month abstinence group the number and percentage of phasically active cells dramatically increased from 15 cells (29\%; test session 1) to 29 neurons (58\%; test session 2) of all neurons recorded. This increase comprised those neurons that exclusively displayed short-duration patterned activity (up from 17-32\%), long-term cyclic alteration (up from 10-22\%), or both (up from 2-4\%). Importantly, this heightened activation of Acb cell firing occurred even though no significant changes in the total number of neurons recorded were observed during the first (103 cells) and second (101 cells) test session across the two groups $\left(\mathrm{F}_{1,20}=0.096, p>0.05\right)$.

\section{Anatomic Distribution}

Coronal sections showing the location of microwire electrodes ( $n=12$ rats) from which Acb neurons were recorded for the control and 1-month abstinence groups are shown in Figure 6. A relatively even distribution of electrode placements was observed within the core and shell for the control (44 core, 36 shell) and 1-month abstinence (41 core, 39 shell) groups. However, an important finding revealed here was that abstinence increased the incidence of phasically active neurons primarily in the core but not shell of the Acb (as defined by Zahm and Brog, 1992). Specifically, there was a significant (three-fold) increase in the number of phasically active Acb neurons recorded in the core during the second test session (ie following 1-month-abstinence, $n=21$ cells) compared to the first test session (ie prior to abstinence, $n=7$ cells; $\left.\chi^{2}=7.0 ; \mathrm{df}=1 ; p<0.01\right)$. In contrast, for the 1 -month abstinence group, no significant differences were observed in the shell across the test sessions (ie $n=8$ cells before $v s \quad n=8$ cells following 1-month abstinence from 


\section{CONTROLS}
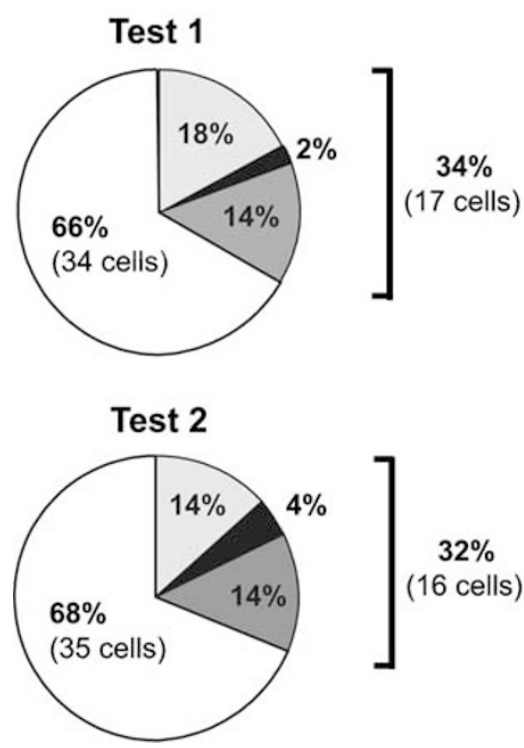

1-MONTH

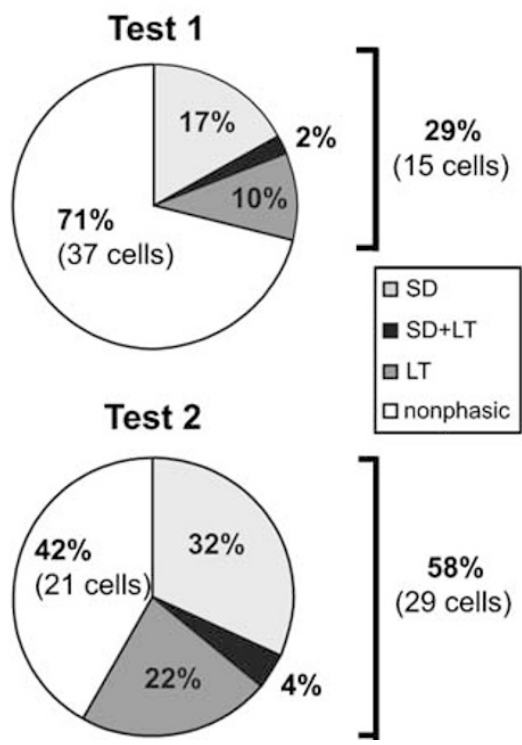

Figure 5 Composite pie charts showing the number and percentage of Acb neurons exhibiting short-duration patterned discharges and/or long-term cyclic alterations for controls (left) and I-month (right) groups across test sessions. For both groups, test I refers to recordings during the last cocaine selfadministration training session. Test 2 refers to recordings the following day (controls) or I-month later (I-month). SD = Acb neurons exhibiting short duration patterned discharges, $\mathrm{LT}=\mathrm{Acb}$ neurons exhibiting long-term cyclic alterations, $\mathrm{SD}+\mathrm{LT}=\mathrm{Acb}$ neurons showing both short duration patterned discharges and long-term cyclic alterations, nonphasic = Acb neurons exhibiting no change in cell firing relative to the reinforced response during selfadministration sessions.

cocaine; $\left.\chi^{2}=0 ; \mathrm{df}=1 ; p>0.05\right)$. Likewise, for the control group, there were no significant differences in the number of neurons recorded in the core $(n=8$ cells during test session 1 vs $n=7$ cells during test session $2, \chi^{2}=0.067$; $\mathrm{df}=1 ; p>0.05)$ or shell $(n=9$ cells during test session 1 vs $n=9$ cells during test session $\left.2, \chi^{2}=0 ; \mathrm{df}=1 ; p>0.05\right)$ of the Acb across test sessions.

\section{DISCUSSION}

The present findings provide the first neurophysiological evidence of a heightened activation of Acb cell firing during resumption of cocaine consumption following a 1-month period of drug abstinence. Specifically, our findings reveal that experimenter-imposed abstinence from cocaine selfadministration in rats causes a dramatic increase in the number and strength of Acb neurons that encode cocainerelated information. Recently, it was reported that cueevoked activation of Acb neurons is maintained after prolonged abstinence from self-administered cocaine (Ghitza et al, 2003). Our findings are consistent with and extend that report by showing that distinct populations of Acb neurons that encode cocaine-directed behaviors become more active during self-administration of the drug following abstinence.

The present study revealed that Acb neurons exhibiting short-duration patterned discharges within seconds of the lever press response for cocaine are enhanced following abstinence. Prior studies have shown that these types of rapid discharges reflect the encoding of associative aspects of the self-administration task (Carelli et al, 1993; Carelli,
2002; Chang et al, 1994; Peoples and West, 1996; Uzwiak et al, 1997). For example, Acb neurons that discharge within seconds before the reinforced response for cocaine appear to encode 'anticipation' of impending drug reward (Carelli et al, 1993; Carelli, 2002; Carelli and Ijames, 2000). In contrast, Acb neurons that exhibit changes in firing rate within seconds following response completion are related to the response (lever press)-reward (cocaine) association. Furthermore, this same population of neurons are selectively activated by stimuli paired with drug infusion (Carelli and Ijames, 2001; Carelli, 2000). The present findings suggest that the encoding of goal-directed behaviors for cocaine become enhanced following a 1-month abstinence period. Importantly, the increased incidence of neurons exhibiting short-duration patterned discharges following abstinence reported here occurred independent of changes in the number of cells recorded, amount of drug consumed, or alterations in lever pressing behavior.

Additionally, a second population of Acb neurons that exhibit long-term cyclic alterations in cell firing within the entire interinfusion interval also increased in number and strength (ie S:B ratio) following abstinence from cocaine. The long-term cyclic alterations reported here are very similar to those shown previously (Peoples and West, 1996). It has been proposed that these long-term discharges may function to translate declining drug levels to increased motivation for the drug and thereby result in increased drug-seeking behavior (Peoples and West, 1996). The finding that this population of Acb neurons is also more activated following abstinence suggests that this property of Acb cell firing becomes enhanced following a period of abstinence from drug self-administration. 


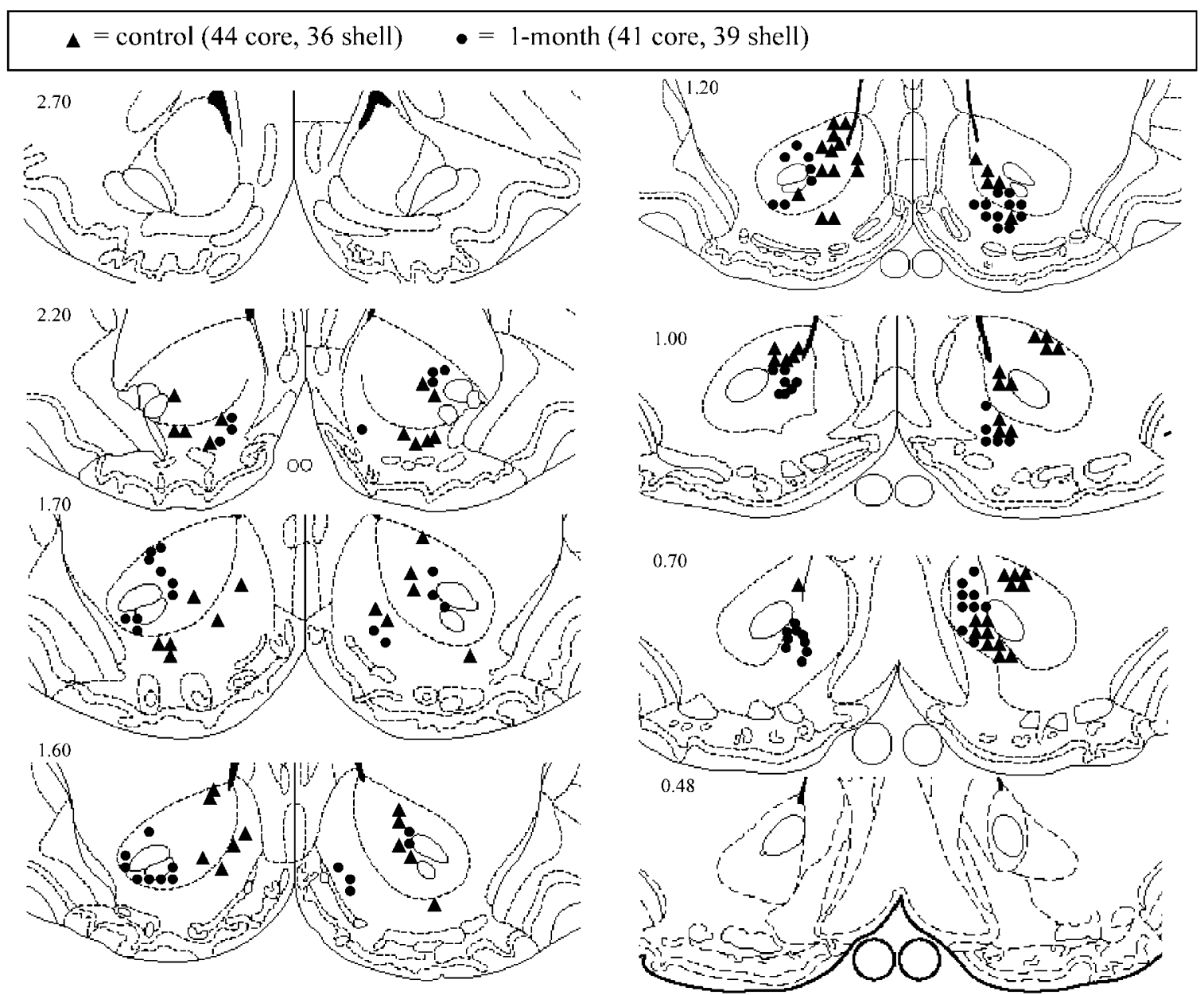

Figure 6 Histological reconstruction of electrode placements. Coronal sections showing placement of microwires from which cell firing was recorded located in the core or shell of the Acb for controls and I-month abstinence groups. Serial sections taken from Paxinos and Watson (I998).

The heightened activation of Acb neurons shown here appears to reflect an enhanced motivation for the drug following abstinence. Specifically, animals were more resistant to extinction following abstinence from cocaine self-administration. These findings are consistent with prior reports. It has been shown that responding during extinction and reinstatement of cocaine-seeking behavior is profoundly influenced by the duration of abstinence from drug self-administration; more responding is typically observed following weeks or months compared to days of abstinence (Grimm et al, 2001; Tran-Nguyen et al, 1998; Lu et al, 2004; Di Ciano and Everitt, 2002; Shaham et al, 2003). Our extinction study extends those reports by showing the same effect of extinction in animals given short $(2 \mathrm{~h})$ daily access to the drug (prior studies examined 3-6h access). Importantly, the lack of changes in self-administration behavior in animals given free access to the drug (ie those animals used in our electrophysiology studies) serves as a critical control. That is, if behavioral rates of responding had dramatically increased following abstinence any changes in cell firing could be attributed solely to alternations in movement.

Abstinence from cocaine self-administration increased the incidence of phasically active neurons in the core (but not the shell) of the Acb. This finding is particularly intriguing given the anatomical and functional differences reported between these subregions (Zahm and Brog, 1992; Zahm and Heimer, 1993; Zahm, 1999; Kelley, 2004). The increased incidence of phasically active neurons in the core is consistent with findings showing that the core, rather than the shell, is essential for cocaine-induced reinstatement of goal-directed behavior (McFarland and Kalivas, 2001). However, it has been also demonstrated that the neurons in the shell, rather than the core, are activated by cocaineassociated stimuli following a period of abstinence (Ghitza et al, 2003). Importantly, our study examined Acb cell firing during resumption of cocaine-seeking behaviors, while the study by Ghitza and co-workers examined Acb activity relative to discriminative stimuli that previously signaled cocaine availability. Thus, the differences in regional activation of Acb cell firing following abstinence between our studies may be related to a differential role of the core and shell in processing information about discriminative stimuli associated with cocaine availability versus resumption of cocaine-seeking and cocaine consumption following abstinence.

The present findings also revealed an enhancement in the strength of the neural signals following a period of 
abstinence, reflected in higher S:B ratios. Although our present study does not reveal precisely how this system changes following abstinence, several possibilities exist. First, it may be the case that a subset of neurons that weakly encoded goal-directed behaviors for cocaine prior to abstinence are activated much more strongly following abstinence. Alternatively, another population of neurons that are not normally activated during goal-directed behaviors (ie nonphasic cells) may become phasically responsive following drug abstinence. While it is important for future studies to examine these possibilities, the findings reported here show cellular evidence of a reorganization of the nucleus accumbens during resumption of cocaine consumption following abstinence.

The increase in the incidence of phasically active Acb neurons reported here could be the consequence of a variety of molecular neuroadaptions resulting from prolonged cocaine abstinence. For example, Kalivas and co-workers have shown that withdrawal from repeated cocaine administration results in multiple cellular adaptations related to glutamate transmission, including decreased activity of the cystine-glutamate exchanger (Baker et al, 2003) and a reduction of the scaffolding protein, Homer $1 \mathrm{bc}$ (Ghasemzadeh et al, 2003; Kalivas et al, 2003). Likewise, alterations in gene expression (Toda et al, 2002) and GABA concentration (Xi et al, 2003) have also been observed following cocaine withdrawal. A number of molecular neuroadaptions related to changes in cAMP dependent protein kinase (PKA), adenylate cyclase, tyrosine hydroxylase and various glutamate receptor subunits were altered in the ventral tegmental area and/or Acb following abstinence from cocaine self-administration ( $\mathrm{Lu}$ et al, 2003). Furthermore, increased dendritic branching and spine density of Acb medium spiny neurons has been shown following a 1-month cocaine-free period (Robinson et al, 2001). Alternatively, the increased incidence of phasically active cells may not be directly related to the molecular neuroadaptions noted here but may reflect, for example, an enhanced afferent activation of Acb cells (eg from the basolateral amygdala or prefrontal cortex) following abstinence. Future studies are needed to determine the precise factors that contribute to the enhanced activation of Acb neurons observed during resumption of cocaine-seeking and cocaine consumption following abstinence.

Nevertheless, our findings reveal that abstinence from cocaine increases the incidence of Acb neurons that process cocaine-related information. We have previously shown that distinct populations of Acb neurons selectively encode information about drug (cocaine) versus natural (water/ food) reward (Carelli et al, 2000). The dramatic increase in the incidence of Acb neurons that encode various aspects of goal-directed behavior for cocaine reported here puts into question whether these independent neuronal circuits remain intact following drug cessation. For the cocaine addict, abstaining from drug use often proves to be extremely difficult. The greater percentage of Acb neurons that encode goal-directed behavior for cocaine after abstinence may reflect a form of plasticity that contributes to the inability of cocaine addicts to remain drug free.

\section{ACKNOWLEDGEMENTS}

This research was supported by NIDA DA14339 to RMC and NIDA Training Grant DA07244 to JAH. We thank Yvette Peters and Robert Wheeler for helpful suggestions on the manuscript and Jay Elliott for help with data analysis.

\section{REFERENCES}

Ahmed SH, Koob GF (2005). Transition to drug addiction: a negative reinforcement model based on an allostatic decrease in reward function. Psychopharmacology 25 [Epub ahead of print].

Baker DA, McFarland K, Lake RW, Shen H, Tang XC, Toda S et al (2003). Neuroadaptations in the cystine-glutamate exchange underlie cocaine relapse. Nat Neurosci 6: 743-749.

Caine SB, Lintz R, Koob GF (1993). In: Sahgal A (ed) Behavioral Neuroscience: A Practical Approach. Oxford UP: Oxford. pp 117-143.

Carelli RM (2000). Activation of accumbens cell firing by stimuli associated with cocaine delivery during self-administration. Synapse 35: 238-242.

Carelli RM (2002). Nucleus accumbens cell firing during goaldirected behaviors for cocaine $v s$ 'natural' reinforcement. Physiol Behav 76: 379-387.

Carelli RM, Deadwyler SA (1994). A comparison of nucleus accumbens neuronal firing patterns during cocaine self-administration and water reinforcement in rats. J Neurosci 14: 7735-7746.

Carelli RM, Ijames S (2000). Nucleus accumbens cell firing during maintenance, extinction, and reinstatement of cocaine selfadministration behavior in rats. Brain Res 866: 44-54.

Carelli RM, Ijames S, Konstantopoulos J, Deadwyler SA (1999). Examination of factors mediating the transition to behaviorally correlated nucleus accumbens cell firing during cocaine self-administration sessions in rats. Behav Brain Res 104: 127-139.

Carelli RM, Ijames SG (2001). Selective activation of accumbens neurons by cocaine-associated stimuli during a water/cocaine multiple schedule. Brain Res 907: 156-161.

Carelli RM, Ijames SG, Crumling AJ (2000). Evidence that separate circuits in the nucleus accumbens encode cocaine $v s$ 'natural' (water and food) reward. J Neurosci 20: 4255-4266.

Carelli RM, King VC, Hampson RE, Deadwyler SA (1993). Firing patterns of nucleus accumbens neurons during cocaine selfadministration in rats. Brain Res 626: 14-22.

Carelli RM, Wightman RM (2004). Functional microcircuitry in the accumbens underlying drug addiction: insights from real-time signaling during behavior. Curr Opin Neurobiol 14: 763-768.

Chang JY, Sawyer SF, Lee RS, Woodward DJ (1994). Electrophysiological and pharmacological evidence for the role of the nucleus accumbens in cocaine self-administration in freely moving rats. J Neurosci 14: 1224-1244.

Di Ciano P, Everitt BJ (2002). Reinstatement and spontaneous recovery of cocaine-seeking following extinction and different durations of withdrawal. Behav Pharmacol 13: 397-405.

Everitt BJ, Wolf ME (2002). Psychomotor stimulant addiction: a neural systems perspective. J Neurosci 22: 3312-3320.

Gawin FH (1991). Cocaine addiction: psychology and neurophysiology. Science 251: 1580-1586.

Ghasemzadeh MB, Permenter LK, Lake R, Worley PF, Kalivas PW (2003). Homer1 proteins and AMPA receptors modulate cocaine-induced behavioural plasticity. Eur J Neurosci 18: $1645-1651$.

Ghitza UE, Fabbricatore AT, Prokopenko V, Pawlak AP, West MO (2003). Persistent cue-evoked activity of accumbens neurons after prolonged abstinence from self-administered cocaine. J Neurosci 23: 7239-7245. 
Green JD (1958). A simple microelectrode for recording from the central nervous system. Nature 182: 962.

Grimm JW, Hope BT, Wise RA, Shaham Y (2001). Neuroadaptation. Incubation of craving after withdrawal. Nature 412: 141-142.

Ito R, Robbins TW, Everitt BJ (2004). Differential control over cocaine-seeking behavior by nucleus accumbens core and shell. Nat Neurosci 7: 389-397.

Kalivas PW, McFarland K, Bowers S, Szumlinski K, Xi ZX, Baker D (2003). Glutamate transmission and addiction to cocaine. Ann NY Acad Sci 1003: 169-175.

Kelley AE (2004). Ventral striatal control of appetitive motivation: role in ingestive behavior and reward-related learning. Neurosci Biobehav Rev 27: 765-766.

Koob GF, Le Moal M (2001). Drug addiction, dysregulation of reward, and allostasis. Neuropsychopharm 24: 97-129.

Koob GF, LeMoal M (1997). Drug abuse: hedonic homeostatic dysregulation. Science 278: 52-57.

Lu L, Grimm JW, Dempsey J, Shaham Y (2004). Cocaine seeking over extended withdrawal periods in rats: different time courses of responding induced by cocaine cues versus cocaine priming over the first 6 months. Psychopharmacology 176: 101-108.

$\mathrm{Lu}$ L, Grimm JW, Shaham Y, Hope BT (2003). Molecular neuroadaptations in the accumbens and ventral tegmental area during the first 90 days of forced abstinence from cocaine selfadministration in rats. J Neurochem 85: 1604-1613.

McFarland K, Kalivas PW (2001). The circuitry mediating cocaineinduced reinstatement of drug-seeking behavior. J Neurosci 21: 8655-8663.

Nicolelis MAL (1999). Methods for Neural Ensemble Recordings. CRC Press: Boca Raton, FL. 257pp.

Nicolelis MAL, Ghazanfar AA, Faggin BM, Votaw S, Oliveira LMO (1997). Reconstructing the engram: simultaneous, multisite, may single neuron recordings. Neuron 18: 529-537.

O'Brien CP (1997). A range of research-based pharmacotherapies for addiction. Science 278: 66-70.

Paxinos G, Watson C (1998). The Rat Brain in Stereotaxic Coordinates. Academic Press: San Diego, CA. 256pp.

Peoples LL, Gee F, Bibi R, West MO (1998a). Phasic firing time locked to cocaine self-infusion and locomotion: dissociable firing patterns of single nucleus accumbens neurons in the rat. J Neursci 18: 7588-7598.
Peoples LL, Uzwiak AJ, Guyette FX, West MO (1998b). Tonic inhibition of single nucleus accumbens neurons in the rat: a predominant but not exclusive firing pattern induced by cocaine self-administration sessions. Neuroscience 86: 13-22.

Peoples LL, West MO (1996). Phasic firing of single neurons in the rat nucleus accumbens correlated with the timing of intravenous cocaine self-administration. J Neurosci 16: 3459-3473.

Robinson TE, Gorny G, Mitton E, Kolb B (2001). Cocaine selfadministration alters the morphology of dendrites and dendritic spines in the nucleus accumbens and neocortex. Synapse 39: 257-266.

Shaham Y, Shalev U, Lu L, De Wit H, Stewart J (2003). The reinstatement model of drug relapse: history, methodology and major findings. Psychopharmacology 168: 3-20.

Toda S, McGinty JF, Kalivas PW (2002). Repeated cocaine administration alters the expression of genes in corticolimbic circuitry after a 3-week withdrawal: a DNA macroarray study. J Neurochem 82: 1290-1299.

Tran-Nguyen LTL, Fuchs RA, Coffey GP, Baker DA, O'Dell LE, Neisewander JL (1998). Time-dependent changes in cocaineseeking behavior and extracellular dopamine levels in the amygdala during cocaine withdrawal. Neuropsychopharmacology 19: 48-59.

Uzwiak AJ, Guyette FX, West MO, Peoples LL (1997). Neurons in accumbens subterritories of the rat: phasic firing time-locked within seconds of intravenous cocaine infusion. Brain Res 767: 363-369.

Wise RA (1984). Neural mechanisms of the reinforcing actions of cocaine. NIDA Res Mono 50: 15-33.

Xi ZX, Ramamoorthy S, Shen H, Lake R, Samuvel DJ, Kalivas PW (2003). GABA transmission in the nucleus accumbens is altered after withdrawal from repeated cocaine. I Neurosci 23: 3498-3505.

Zahm DS (1999). Functional-anatomical implications of the nucleus accumbens core and shell subterritories. Ann NY Acad Sci 877: 113-128.

Zahm DS, Brog JS (1992). On the significance of subterritories in the 'accumbens' part of the rat striatum. Neurosci 50: 751-767.

Zahm DS, Heimer L (1993). Specificity in the efferent projections of the nucleus accumbens in the rat: comparison of the rostral pole projection patterns with those of the core and shell. J Comp Neurol 327: 220-232. 